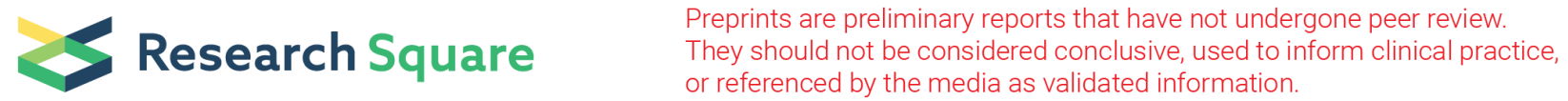

\section{Cardiorespiratory Fitness is Associated with Multiple other Physical Fitness Components in 7- 14-year-olds: A Cross-Sectional Study}

Mario Kasović

Sveučilište u Zagrebu Kineziološki Fakultet: Sveuciliste u Zagrebu Kinezioloski fakultet

Lovro Štefan ( $\square$ lovro.stefan1510@gmail.com)

Sveuciliste u Zagrebu Kinezioloski fakultet https://orcid.org/0000-0002-7705-7801

Vilko Petrić

Faculty of Teacher Education

Vesna Štemberger

Faculty of Education

Iva Blažević

Faculty of Educational Science

Research article

Keywords: aerobic capacity, musculoskeletal fitness, school-aged children, testing

Posted Date: December 8th, 2020

DOI: https://doi.org/10.21203/rs.3.rs-122531/v1

License: (c) (i) This work is licensed under a Creative Commons Attribution 4.0 International License.

Read Full License

Version of Record: A version of this preprint was published at BMC Public Health on April 7th, 2021. See the published version at https://doi.org/10.1186/s12889-021-10702-2. 


\section{Abstract}

\section{Background}

Although evidence suggests that cardiorespiratory fitness is the most important component associated with future health, little is known of how it is associated with multiple other physical fitness components. Since various physical fitness aspects do not change the same as cardiorespiratory fitness during childhood, it is necessary to establish possible associations between cardiorespiratory fitness and other physical fitness components in children. Therefore, the main purpose of the study was to test the associations between cardiorespiratory fitness with motor performance and body size in 7-14-year-old children.

\section{Methods}

In this cross-sectional study, we recruited 1612 children (52.5\% girls). Health-related physical fitness components included: 1 ) body-mass index $\left(\mathrm{kg} / \mathrm{m}^{2}\right)$ calculated from height and weight (measure of body size), 2) sit-and-reach test (measure of flexibility), 3) standing long jump (measure of explosive strength), 4) sit-ups in $30 \mathrm{sec}$ (measure of repetitive strength), 5) 10x5 shuttle run test (measure of agility) and 6) $20-\mathrm{m}$ shuttle run test (measure of aerobic capacity). The associations were performed using generalized estimating equations with $\beta$ coefficients.

\section{Results}

After adjusting for age, cardiorespiratory fitness was associated with sit-and-reach test $(\beta=0.13, p<0.001)$, standing long jump $(\beta=0.59, p<0.001)$, sit-ups in $30 \sec (\beta=0.53, p<0.001)$ and $10 \times 5$ shuttle run test $(\beta=-0.56, p<0.001)$ in boys. In girls, cardiorespiratory fitness was associated with body-mass index $(\beta=-0.12, p<0.001)$, sit-and-reach test $(\beta=0.21, p<0.001)$, standing long jump $(\beta=0.25, p<0.001)$, sit-ups in $30 \sec (\beta=0.36, p<0.001)$ and $10 \times 5$ shuttle run test $(\beta=-0.40, p<0.001)$. No significant associations between cardiorespiratory fitness and body-mass index in boys were observed.

\section{Conclusions}

Although significant, cardiorespiratory fitness is weakly to moderately associated with other physical fitness components, pointing out that such measure should be tested separately from other aspects of physical fitness in school-aged children. 


\section{Background}

Physical fitness has become an important non-communicable factor associated with well-being and health in the past two decades [1, 2]. Evidence suggests that higher levels of physical fitness in youth may prevent from cardiovascular, metabolic and mental diseases later in life [3-7], highlighting the importance of tracking characteristics of physical fitness from childhood to adulthood [8]. Moreover, studies have recognized that most risk factors attributed to chronic diseases in adulthood begin during childhood $[2,9,10]$, pointing out that interventions aiming to enhance physical fitness at younger age for future health benefits are warranted [11].

Physical fitness represents a multifactorial construct and an integrated measure of body composition, cardiorespiratory fitness, muscular fitness, speed/agility and flexibility [2]. Although all aspects of physical fitness seem to be important [2], cardiorespiratory fitness has been the strongest predictor of morbidity and mortality in both men and women independently of other risk factors [12, 13]. In recent years, the level of cardiorespiratory fitness has declined dramatically in school-aged children, increasing the prevalence of overweight/obesity [14] and not meeting the recommended levels of physical activity [15].

Although cardiorespiratory fitness has been associated with fundamental movement skill proficiency [16], little evidence has been provided regarding associations to other physical fitness components [11]. A study by Venckunas et al. [11] conducted among $>15,000$ Lithuanian schoolchildren has shown that standing long jump and agility shuttle run are the strongest predictors of cardiorespiratory fitness (number of completed endurance shuttle run stages) with $\approx 10 \%$ of the variance shared in performance in these tests, followed by bent arm hang time, sit-ups $(\approx 6-7 \%)$ and sit-and-reach test $(\approx 3 \%)$. According to aforementioned, cardiorespiratory fitness has been only weakly associated with multiple other aspects of physical fitness, concluding that this measure should be tested as a separate physical fitness component within the school system. Moreover, biological and environmental changes in cardiorespiratory fitness do not follow the changes in other physical fitness components [11], i.e. the associations between cardiorespiratory fitness and other aspects of physical fitness remain unclear.

Therefore, the main purpose of the study was to test the associations between cardiorespiratory fitness with motor performance and body size in 7-14-year-old children. We hypothesized, that cardiorespiratory fitness would be positively associated with muscular and motor competence, yet inversely associated with body size. If the associations happen to be weak, this will imply that cardiorespiratory fitness is a single construct of overall physical fitness, which should be measured independently of multiple other physical fitness components.

\section{Methods}

\section{Study participants}


In this cross-sectional study, the participants were children aged 7-14 years from the city of Zagreb. At the first stage, a random sampling approach was used to select primary schools. Randomization of schools was done with replacement by drawing school codes on slips of paper from a box, with each school having equal probability of selection. At the second stage, we randomly selected one class presenting one age group within each school. Finally, 12 primary schools with 96 classes $(12$ schools $x 8$ classes) and 1950 students were selected. Of these, 338 did not have a measure of cardiorespiratory fitness or were absent from school during the testing day. Analyses were performed on 1612 school aged children (response rate $=82.7 \%, 52.5 \%$ girls). All procedures performed in this study were anonymous and were conducted according to Declaration of Helsinki. The study was approved by the Faculty of Kinesiology, University of Zagreb, Croatia. The informed consent voluntarily was signed by the participants, participants' parents or their guardians.

\section{Cardiorespiratory fitness}

The 20-m shuttle run test was used to assess the level of cardiorespiratory fitness [2-4, 11]. Detailed information about the testing procedure is described elsewhere $[2-4,11]$. The final score was written as the number of stages completed during every-minute increasing pace of 20-m shuttle run test from walking to running. The result in 20 -m shuttle run test provides a valid estimate of treadmill maximal oxygen uptake in youth [17].

\section{Multiple other physical fitness components}

Other health-related physical fitness components included: 1) body-mass index $\left(\mathrm{kg} / \mathrm{m}^{2}\right)$ calculated from height and weight (measure of body size), 2) sit-and-reach test (measure of flexibility), 3) standing long jump (measure of explosive strength), 4) sit-ups in $30 \mathrm{sec}$ (measure of repetitive strength) and 5) $10 \times 5$ shuttle run test (measure of agility). We followed the procedure of previously published study on the same topic $[11,18]$. Height and weight were objectively measured by using stadiometer and digital scale with a precision of $0.1 \mathrm{~cm}$ and $01 \mathrm{~kg}$. Body-mass index was calculated by dividing weight in $\mathrm{kg}$ with height in $\mathrm{m}^{2}$ [weight $(\mathrm{kg}) /$ height $(\mathrm{m})^{2}$ ]. Sit-and-reach test was used to assess the level of lower body flexibility while trying to reach forward as far as possible keeping knees straight in a sitting position with feet vertical to the ground. Standing broad jump tests jumping distance from a standing start ('frog leap'). While performing the jumps, each child was asked to bend their knees with their arms in front of them, parallel to the ground, then to swing both arms, push off vigorously and jump forward as far as possible, trying to land with their feet together and stay upright [18]. Sit-up test evaluates abdominal muscles function as number of sit-ups completed from lying position (knees bent at a $90^{\circ}$ ) in $30 \mathrm{~s}$. Children were seated on the floor, backs straight, hands clasped behind their neck, knees bent at $90^{\circ}$ with heels and feet flat on the mat. They then lay down on their backs, shoulders touching the mat, and returned to the sitting position with their elbows out in front to touch their knees, keeping the hands clasped behind their neck the whole time [18]. Agility shuttle run measures the time required to complete $50 \mathrm{~m}$ shuttle run test from a standing start during which the participants run forth and back five times to complete five $10 \mathrm{~m}$ laps [11]. 
According to previous studies, testing procedures performed in the study were standardized in order to minimize the effects of environmental factors and to avoid fatigue [11]. During the testing, children wore light T-shirt, shorts and training shoes. On the first day of measurement, tests were administrated and performed by children in following order: 1) body-mass index, 2) sit-and-reach test, 3) standing long jump, 4) sit-ups in $30 \mathrm{sec}$ and 5) $10 \times 5$ shuttle run test. On the second day, 20-m shuttle run test was performed [19].

\section{Data analysis}

Basic descriptive statistics of the study participants are presented as mean \pm standard deviation. Kolmogorov-Smirnov test was applied to identify outliers, which were subsequently excluded. The associations between the cardiorespiratory fitness (unadjusted model and model adjusted for age) with other multiple physical fitness components were determined by using generalized estimating equations. The working correlation matrix was set to exchangeable in all analyses. As highlighted in previous studies [20], the regression models were tested for several assumptions: 1) multicollinearity diagnostics using variance inflation index, 2) normality of residuals using the normal probability plot and histogram of residuals, and 3 ) heteroscedasticity using the standardized residuals vs. predicted plot. All assumptions were met for all regression models. Sex-specific analyses were performed, since there were significant differences between boys and girls in all physical fitness tests $(p<0.001$; except for bodymass index, $p=0.210$ ). Two-sided $p$-values were used, and significance was set at $a<0.05$. All the analyses were calculated in Statistical Packages for Social Sciences v.23 (SPSS, Chicago, IL, United States).

\section{Results}

Basic descriptive statistics of the study participants are presented in Table 1. Boys were taller, heavier and had higher body-mass index values. Boys performed better in all physical fitness tests, except for sit-andreach test in favor to girls. 
Table 1

Basic descriptive statistics of the study participants $(N=1612)$

\begin{tabular}{|lllll|}
\hline Study & $\begin{array}{l}\text { Total sample } \\
\text { variables }\end{array}$ & $\begin{array}{l}\text { Boys } \\
(N=1612)\end{array}$ & $\begin{array}{l}\text { Girls } \\
(N=765)\end{array}$ & p-value* \\
\hline & Mean (SD) & Mean (SD) & Mean (SD) & \\
\hline Age (years) & $9.7(2.4)$ & $9.8(2.4)$ & $9.6(2.3)$ & 0.148 \\
\hline Height (cm) & $151.0(176)$ & $152.0(19.4)$ & $150.2(15.7)$ & 0.046 \\
\hline Weight (kg) & $45.1(19.1)$ & $46.5(13.3)$ & $43.9(14.04)$ & 0.006 \\
\hline Body-mass index (kg/m²) & $20.2(3.4)$ & $21.6(3.6)$ & $19.9(3.3)$ & $<0.001$ \\
\hline Sit-and-reach test (cm) & $20.4(8.3)$ & $17.6(8.3)$ & $23.0(7.3)$ & $<0.001$ \\
\hline Standing long jump (cm) & $158.5(43.5)$ & $164.4(38.9)$ & $153.1(46.7)$ & $<0.001$ \\
\hline Sit-ups in 30 sec (\#) & $17.1(7.0)$ & $17.8(7.2)$ & $16.5(6.8)$ & $<0.001$ \\
\hline $10 \times 5$ shuttle run (sec) & $23.1(3.0)$ & $22.6(3.2)$ & $23.6(2.8)$ & $<0.001$ \\
\hline 20 -m shuttle run (level) & $4.3(1.9)$ & $4.9(2.2)$ & $3.9(1.4)$ & $<0.001$ \\
\hline *denotes significant differences between boys and girls; & & \\
\hline$p<0.05$ & & & & \\
\hline
\end{tabular}

The associations between cardiorespiratory fitness and multiple other physical fitness components in boys are presented in Table 2. In unadjusted model, variance of performance in standing long jump (40.0\%), $10 \times 5$ shuttle run (36.0\%) and sit-ups in $30 \mathrm{sec}$ (32.5\%) were each explained by cardiorespiratory fitness the strongest, followed by weaker but still significant association by cardiorespiratory fitness with sit-and-reach test (1.2\%). When models were adjusted for age, variance of performance in standing long jump (34.8\%), $10 \times 5$ shuttle run (31.4\%) and sit-ups in $30 \mathrm{sec}(28.1 \%)$ remained the strongest predictors of cardiorespiratory fitness, followed by sit-and-reach test $(1.7 \%)$ 
Table 2

The associations between cardiorespiratory fitness and multiple other physical fitness components in boys $(N=765)$

\begin{tabular}{|llll|}
\hline Study variables & $\beta$ coefficient* & t-value & $p$-value \\
\hline Body-mass index (kg/m²) & & & \\
\hline Unadjusted model & 0.01 & 0.118 & 0.906 \\
\hline Model adjusted by age & 0.02 & 0.361 & 0.718 \\
\hline Sit-and-reach test (cm) & & & \\
\hline Unadjusted model & 0.11 & 2.897 & 0.004 \\
\hline Model adjusted by age & 0.13 & 3.497 & $<0.001$ \\
\hline Standing long jump (cm) & & & \\
\hline Unadjusted model & 0.63 & 21.127 & $<0.001$ \\
\hline Model adjusted by age & 0.59 & 19.900 & $<0.001$ \\
\hline Sit-ups in 30 sec (\#) & & & \\
\hline Unadjusted model & 0.57 & 18.332 & $<0.001$ \\
\hline Model adjusted by age & 0.53 & 17.369 & $<0.001$ \\
\hline 10×5 shuttle run (sec) & & & \\
\hline Unadjusted model & -0.60 & -19.739 & $<0.001$ \\
\hline Model adjusted by age & -0.56 & -18.165 & $<0.001$ \\
\hline *standardized $\beta$ coefficient; & & & \\
\hline$p<0.05$ & & & \\
\hline
\end{tabular}

The associations between cardiorespiratory fitness and multiple other physical fitness components in girls are presented in Table 3. In unadjusted model, variance of performance in $10 \times 5$ shuttle run (22.1\%) was the strongest predictor explained by cardiorespiratory fitness, followed by sit-ups in $30 \mathrm{sec}(16.8 \%)$, standing long jump (9.6\%) and sit-and-reach test (7.3\%). When models were adjusted for age, variance of performance in $10 \times 5$ shuttle run (16.3\%), sit-ups in $30 \mathrm{sec}(13.0 \%)$ and standing long jump (6.3\%) remained the strongest predictors of cardiorespiratory fitness, followed by sit-and-reach test (4.4\%) and body-mass index (1.4\%). 
Table 3

The associations between cardiorespiratory fitness and multiple other physical fitness components in girls $(N=857)$

\begin{tabular}{|llll|}
\hline Study variables & $\beta$ coefficient & $t$-value & $p$-value \\
\hline Body-mass index (kg/m²) & & & \\
\hline Unadjusted model & -0.05 & -1.283 & 0.200 \\
\hline Model adjusted by age & -0.12 & -3.597 & $<0.001$ \\
\hline Sit-and-reach test (cm) & & & \\
\hline Unadjusted model & 0.27 & 7.851 & $<0.001$ \\
\hline Model adjusted by age & 0.21 & 6.528 & $<0.001$ \\
\hline Standing long jump (cm) & & & \\
\hline Unadjusted model & 0.31 & 8.838 & $<0.001$ \\
\hline Model adjusted by age & 0.25 & 7.698 & $<0.001$ \\
\hline Sit-ups in 30 sec (\#) & & & \\
\hline Unadjusted model & 0.41 & 12.403 & $<0.001$ \\
\hline Model adjusted by age & 0.36 & 11.457 & $<0.001$ \\
\hline $10 \times 5$ shuttle run (sec) & & & \\
\hline Unadjusted model & -0.47 & -14.899 & $<0.001$ \\
\hline Model adjusted by age & -0.40 & -12.531 & $<0.001$ \\
\hline *standardized $\beta$ coefficient; & & & \\
\hline$p<0.05$ & & & \\
\hline
\end{tabular}

\section{Discussion}

The main purpose of the study was to test the associations between cardiorespiratory fitness with motor performance and body size in 7-14-year-old children. The main findings are: 1) cardiorespiratory fitness predicts between $1-40 \%$ of the variance in performance in multiple other physical fitness components in boys, 2) in girls, cardiorespiratory fitness predicts between $7-22 \%$ of the variance in performance in multiple other physical fitness components and 3) when adjusting for age, the percentage of variance shared between cardiorespiratory fitness and multiple other physical fitness components slightly declines.

Our results of cardiorespiratory fitness being most strongly associated to $10 \times 5$ shuttle run, standing long jump and sit-ups in $30 \mathrm{sec}$ are in line with previous findings obtained among a large sample of 
Lithuanian school aged children [11]. Specifically, a study by Venckunas et al. [11] has shown that variance of performance in $10 \times 5$ shuttle run and standing long jump were each explained by cardiorespiratory fitness the strongest $(>10 \%)$, followed by the association between cardiorespiratory fitness with the abilities in bent arm hang and sit-ups (cardiorespiratory fitness explaining $\sim 6.5 \%$ of the variance of the performance in these tests), as well as in balance and sit-and-reach tasks (aerobic capacity significantly explaining $\sim 3 \%$ of the variance). It has been hypothesized, that for $10 \times 5$ shuttle run and standing long jump performance, movement patterns are similar and the same muscle groups (i.e. leg extensors) need to be involved for locomotion [11]. Another potential mechanism may be the nature of these activities, which require different jumping, accelerating and decelerating performances deserving for intrinsic musculoskeletal characteristics, synchronizing upper and lower body and gaining appropriate momentum [11]. Also, the aforementioned tasks fall under weight-bearing exercises, which share similar moving patterns. Indeed, studies have shown that cardiorespiratory fitness is associated with anaerobic functional capacities required for performing agility and power/strength tasks [20].

The strongest associations between cardiorespiratory and muscular fitness are not surprising, since higher levels of these components reduce the risk of all-cause mortality [21,22] and are often interrelated [11]. From the perspective in sport, evidence suggests that low cardiorespiratory fitness may be compensated for additional muscle training stimulus in aerobic endurance athletes [23], pointing out that all physical fitness components should be equally developed and enhanced across the lifespan. This supports the findings from previous studies, stating that being involved in endurance sport is not associated with an increased life expectancy [24]. Therefore, physical fitness, as a multifactorial construct, is the best non-communicable factor remotely associated to health [3-7]. Nevertheless, the critical period when physical fitness (especially cardiorespiratory fitness) should be trained is during the childhood period, since it successfully predicts the development of cardiovascular diseases in later life [4].

This study has a few limitations. First, by using a cross-sectional design, we cannot determine the causality of the association, that is multiple other physical fitness components were associated to cardiorespiratory fitness. Second, we randomly selected schools and classes for the purpose of this study and achieved an acceptable response rate. Nevertheless, more physically active families are more prone to participating in the studies of such nature [25]. Thus, potential selection bias cannot be excluded. Third, the proxy of cardiorespiratory fitness was assessed through the 20-m shuttle run test. Although this test has been widely used and the reliability and validity properties have been confirmed [4], treadmill or bicycle ergometers may have given somewhat different maximal oxygen uptake values and associations between cardiorespiratory fitness with multiple other physical fitness components. Therefore, future research on the same topic needs to be longitudinal with more objective methods to assess the level of cardiorespiratory fitness in school aged children.

\section{Conclusions}


This study confirms that cardiorespiratory fitness is most strongly associated with $10 \times 5$ shuttle run and standing long jump, followed by sit-ups in $30 \mathrm{sec}$, sit-and reach test and body-mass index. Although significant, the associations between cardiorespiratory fitness and multiple other physical fitness components are weak to moderate, which is an important information of testing cardiorespiratory fitness as a separate physical fitness component in school settings.

\section{Declarations}

Ethics approval and consent to participate: The study was approved by the Faculty of Kinesiology, University of Zagreb, Croatia. The informed consent voluntarily was signed by the participants, participants' parents or their guardians.

Consent for publication: The informed consent voluntarily was signed by the participants, participants' parents or their guardians.

Availability of data and materials: The datasets used and/or analyzed during the current study are available from the corresponding author on reasonable request.

Competing interests: The authors declare that they have no competing interests.

Funding: The paper was self-funded.

Authors' contributions: VP conducted the study. LŠ analyzed the data. MK, LŠ, VP and TV wrote and drafted the manuscript. The author(s) read and approved the final version of the manuscript.

Acknowledgements: The authors would like to thank all the physical education teachers, children and their parents or guardians for enthusiastic participation in the study.

\section{References}

1. Catley MJ, Tomkinson GR. Normative health-related fitness values for children: analysis of 85347 test results on 9-17-year-old Australians since 1985. Br J Sports Med. 2013;47:98-108.

2. Ortega FB, Ruiz JR, Castillo MJ, Sjöström M. Physical fitness in childhood and adolescence: a powerful marker of health. Int J Obes (Lond). 2008;32:1-11.

3. Ortega FB, Artero EG, Ruiz JR, España-Romero V, Jiménez-Pavón D, Vicente-Rodriguez G, et al. HELENA study. Physical fitness levels among European adolescents: the HELENA study. Br J Sports Med. 2011;45:20-9.

4. Ruiz JR, Castro-Piñero J, Artero EG, Ortega FB, Sjöström M, Suni J, et al. Predictive validity of healthrelated fitness in youth: a systematic review. Br J Sports Med. 2009;43:909-23.

5. Benson AC, Torode ME, Singh MA. Muscular strength and cardiorespiratory fitness is associated with higher insulin sensitivity in children and adolescents. Int J Pediatr Obes. 2006;1:222-31. 
6. Antero-Jacquemin J, Pohar-Perme M, Rey G, Toussaint JF, Latouche A. The heart of the matter: yearssaved from cardiovascular and cancer deaths in an elite athlete cohort with over a century of followup. Eur J Epidemiol. 2018;33:531-43.

7. Myers J, Prakash M, Froelicher V, Do D, Partington S, Atwood JE. Exercise capacity and mortality among men referred for exercise testing. N Engl J Med. 2002;346:793-801.

8. Malina RM. Physical activity and fitness: Pathways from childhood to adulthood. Am J Hum Biol. 2001;13:162-72.

9. Dwyer T, Magnussen CG, Schmidt MD, Ukoumunne OC, Ponsonby AL, Raitakari OT, et al. Decline in physical fitness from childhood to adulthood associated with increased obesity and insulin resistance in adults. Diabetes Care. 2009;32:683-7.

10. Ruiz JR, Cavero-Redondo I, Ortega FB, Welk GJ, Andersen LB, Martinez-Vizcaino V. Cardiorespiratory fitness cut points to avoid cardiovascular disease risk in children and adolescents; what level of fitness should raise a red flag? A systematic review and meta-analysis. Br J Sports Med. 2016;50:1451-8.

11. Venckunas T, Mieziene B, Emeljanovas A. Aerobic capacity is related to multiple other aspects of physical fitness: a study in a large sample of Lithuanian schoolchildren. Front Physiol. 2018;9:1797.

12. Chase NL, Sui $X$, Lee DC, Blair SN. The association of cardiorespiratory fitness and physical activity with incidence of hypertension in men. Am J Hypertens. 2009;22:417-24.

13. Kodama S, Saito K, Tanaka S, Maki M, Yachi Y, Asumi M, et al. Cardiorespiratory fitness as a quantitative predictor of all-cause mortality and cardiovascular events in healthy men and women: a meta-analysis. JAMA. 2009;301:2024-35.

14. Albon HM, Hamlin MJ, Ross JJ. Secular trends and distributional changes in health and fitness performance variables of 10-14-year-old children in New Zealand between 1991 and 2003. Br J Sports Med. 2010;44:263-9.

15. Pahkala K, Hernelahti M, Heinonen OJ, Raittinen P, Hakanen M, Lagström H, et al. Body mass index, fitness and physical activity from childhood through adolescence. $\mathrm{Br} J$ Sports Med. 2013;47:71-7.

16. Okely AD, Booth ML, Patterson JW. Relationship of cardiorespiratory endurance to fundamental movement skill proficiency among adolescents. Pediatr Exerc Sci. 2001;13:380-91.

17. Paradisis GP, Zacharogiannis E, Mandila D, Smirtiotou A, Argeitaki P, Cooke CB. Multi-stage 20-m shuttle run fitness test, maximal oxygen uptake and velocity at maximal oxygen uptake. J Hum Kinet. 2014;41:81-7.

18. Štefan L, Paradžik P, Sporiš G. Sex and age correlations of reported and estimated physical fitness in adolescents. PLoS ONE. 2019;14:e0219217.

19. Venckunas T, Emeljanovas A, Mieziene B, Volbekiene V. Secular trends in physical fitness and body size in Lithuanian children and adolescents between 1992 and 2012. J Epidemiol Commun Health. 2017;71:181-7.

20. Sinnett AM, Berg K, Latin RW, Noble JM. The relationship between field tests of anaerobic power and 10-km run performance. J Strength Cond Res. 2001;15:405-12. 
21. Kokkinos P, Myers J, Kokkinos JP, Pittaras A, Narayan P, Manolis A, et al. Exercise capacity and mortality in black and white men. Circulation. 2008;117:614-22.

22. García-Hermoso A, Cavero-Redondo I, Ramírez-Vélez R, Ruiz JR, Ortega FB, Lee DC, et al. Muscular Strength as a predictor of all-cause mortality in an apparently healthy population: a systematic review and meta-analysis of data from approximately 2 Million men and women. Arch Phys Med Rehabil. 2018;99:2100-13.

23. Kusy K, Zieliński J. Aerobic capacity in speed-power athletes aged 20-90 years vs endurance runners and untrained participants. Scand J Med Sci Sports. 2014;24:68-79.

24. Antero-Jacquemin J, Pohar-Perme M, Rey G, Toussaint JF, Latouche A. The heart of the matter: yearssaved from cardiovascular and cancer deaths in an elite athlete cohort with over a century of followup. Eur J Epidemiol. 2018;33:531-43.

25. Štefan L, Sorić M, Devrnja A, Podnar H, Mišigoj-Duraković M. Is school type associated with objectively measured physical activity in 15-year-olds? Int J Environ Res Public Health. 2017;14:1417. 